Acta Hispanica (2014) 19: 51-61

\title{
"VOCES Y ESPEJOS" DE ESPIDO FREIRE. HACIA UNA ESTÉTICA DE LA PERVERSIÓN EN EL RELATO ESPECULAR
}

\author{
SAMUEL RODRÍGUEZ RODRÍGUEZ
}

\author{
Université Paris-Sorbonne
}

\begin{abstract}
Resumen: Espido Freire (Bilbao, 1974) es una de las escritoras más interesantes del panorama literario español actual. Ha confesado en numerosas ocasiones su predilección por el cuento. "Voces y espejos", perteneciente al libro de cuentos Juegos míos (2004), se ofrece como paradigma de las obsesiones que pueblan su obra, esto es, las voces y los espejos como inductores del mal. La mise en abyme o el relato especular en tanto que desdoblamiento narrativo -ampliamente estudiada por Lucien Dällenbach- permite a la autora el desarrollo de un alter ego, tan querido por Borges o Cortázar, y que aquí apunta a una voz oculta en nosotros, sutil, apenas perceptible, pero siempre perversa, y que el espejo se encarga de reflejar peligrosamente. Este relato presenta además la particularidad de emplear una mise en abyme doble por su carácter metaliterario, que remite a la propia concepción y recepción del relato dentro de un triángulo macabro entre autor, texto y lector.
\end{abstract}

Palabras clave: Espido Freire, cuento, perversión, "Voces y espejos", Juegos míos, mise en abyme.

\begin{abstract}
Espido Freire (Bilbao, 1974) is one of the most interesting authors of contemporary Spanish literature. She has admitted on numerous occasions her preference for tales. "Voces y espejos" belonging to the storybook Juegos mios (2004), is offered as a paradigm of the obsessions that populate her work: the voices and mirrors as inducers of evil. The mise en abyme while splitting the narrator - widely studied by Lucien Dällenbach - permits the author to develop an alter ego what was so beloved by Borges and Cortázar. And here it aims at a hidden voice in us, which is subtle, barely perceptible, but always evil, which is intended to be reflected by the mirror dangerously. This story also presents the particularity of applying a double mise en abyme for its metaliterary character, what refers to the proper conception and reception of the story in a macabre triangle between the author, text and reader.
\end{abstract}

Key words: Espido Freire, tale, perversion, "Voces y espejos", Juegos míos, mise en abyme.

Espido Freire (Bilbao, 1974), es pese a su relativa juventud una escritora consolidada dentro de las letras hispanas. Publicó su primera novela, Irlanda, con tan solo 23 años, a la que siguieron Donde siempre es octubre (1999) y Melocotones helados (1999) que obtuvo el Premio Planeta, convirtiéndose a los 25 años en la escritora más joven en conseguir este 
"Voces y espejos" de Espido Freire. Hacia una estética de la perversión en el relato especular

prestigioso galardón. Ha publicado otras cuatro novelas (Diabulus in musica, 2001, Nos espera la noche, 2003, Soria Moria, 2007 y La flor del norte, 2011). Otros géneros que ha cultivado son la poesía y el ensayo. Al cuento, su género preferido, ha dedicado cuatro libros: El tiempo huye (2001, Premio NH de relatos), Cuentos malvados (2001), Juegos míos (2004) y El trabajo os hará libres (2008). Confiesa que si empezó escribiendo cuentos fue porque consideraba que eran un medio para poder entrenarse técnicamente al "gran género", la novela. ${ }^{1}$ Sin embargo, progresivamente descubrió las exigencias específicas del cuento, al que ha consagrado la mayor parte de su producción literaria, si bien por el momento sólo ha publicado una pequeña parte. De ella ha dicho el profesor García Galiano que "es la escritor(a) [...] en Europa con más talento para el relato corto."2

Así pues, el objetivo de este artículo es analizar a través de uno de sus cuentos, "Voces y espejos", algunas de las particularidades estético-formales que constituyen la base intrínseca de su obra, especialmente el relato especular o en mise en abyme como constructor de la perversión.

"Voces y espejos" pertenece al libro Juegos míos, una colección de veintitrés relatos divido en tres secciones: "El tiempo huye", "Quedemos para la merienda" y "Bestiario", dedicado a monstruos invisibles cotidianos. "Voces y espejos" se sitúa en la primera sección. Es la historia dentro de la historia que se apodera de la realidad. Es el triunfo de la fantasía más perversa frente a la razón. Friedrich es un editor concienzudo acostumbrado a lidiar con todo tipo de historias. Le llega el manuscrito de Marela, una escritora en decadencia cuya obra discurre cada vez más por las mismas obsesiones: las voces y los espejos. Friedrich lee su relato, "El monstruo del espejo", que le está dedicado. Ella, Marela, escribe frente a la imagen obsesiva del espejo. Entonces, a ritmo de vals, aparecen las voces, siete, que le piden cuentas a Marela por ser ellas sus inspiradoras. Friedrich lee hastiado el relato. Está harto de los mismos motivos: el doble, el espejo. Y el relato continúa. Las voces beben su sangre. Otra vez el rito vampírico, piensa Friedrich. Mira sus venas. Marela se lamenta del alto precio que ha de pagar por su arte. Tan solo en el espejo puede esconderse e incluso ahora le resulta cada vez más difícil escapar de las sombras. Friedrich mira su espejo, se siente inquieto. Las voces dialogan con Marela, vienen definitivamente a por ella. Suena el vals. Debe morir, primeramente su sombra en el espejo y, luego, ella. Sigue sonando el vals. Y Friedrich continúa la lectura sin convencimiento, sólo por disciplina. Marela siente entonces deseos de hacer mal, no quiere morir sola. Pronuncia un nombre, el de Friedrich, y las voces aceptan. A Friedrich le parece gracioso, finalmente no era un relato para publicar sino sólo un juego. Pero se mira en el espejo, su sombra no se mueve. Entonces, el ser en el espejo se aparta. Las voces aparecen desde su espejo y la razón se le escapa. Mientras tanto, Marela termina su historia. Tanto dolor, tanto fingimiento... pero esta vez había valido la pena.

\footnotetext{
${ }^{1}$ Espido FREIRE. "El cuento", in: Escritores en la biblioteca, asequible en: http://www.youtube.com/ watch?v $=\mathrm{eZ} 9 \mathrm{vfMIQwxY}$, fecha de consulta: 8 de diciembre de 2013.

2 Idem.
} 
Como en otros de sus relatos ("Loco con cuchillo"o "Juegos míos" en el libro homónimo) dos historias se oponen en el discurso narrativo. Friedrich y el mundo real, y la historia que se inserta en la principal, el cuento de Marela. Se percibe de modo perfectamente lógico la inserción del discurso paralelo. Es un cuento dentro del cuento. Una mise en abyme. Ambas tramas se imbrican de tal manera que consideramos conveniente un estudio lineal que permita ver cómo están engarzadas. Lo mismo sucede con la perspectiva, construida mediante voces narrativas yuxtapuestas, dentro de dos espacios opuestos, el real y el imaginario, que terminan uniéndose, dando como resultado un diseño y estilo característicos en la autora que veremos paso a paso a continuación.

Una cita de Rilke abre el relato: "Sí, es verdad que las primaveras te necesitaban". También Rilke y sus Elegías de Duino preceden Irlanda. El hombre, su existencia, su muerte, entendidos como una misión, la misión. La literatura es un microuniverso de la vida. Es todo y nada. Engloba la existencia, y abre las puertas a la belleza. Pero "la belleza no es nada sino el principio de lo terrible [...]. Todo ángel es terrible" ${ }^{3}$ y precisamente este relato metaliterario aborda los peligros imprevistos del "inofensivo" arte de narrar historias.

Espido Freire se basa en la sugerencia como mecanismo de construcción de la trama. Desliza sutilmente elementos que pueden pasar desapercibidos al inicio pero que cobran forma con el tiempo. Así pues, el relato comienza con una exposición (83-84) donde se presenta el mundo cotidiano de Friedrich: los libros, las pilas de trabajo que él, primorosamente, lee y ordena. Su mundo es la razón. Pero encontramos desde la primera página la tragedia que se cierne sobre él: “[eran] días en los que sólo le apetecía desplomarse sobre la cama al llegar a casa y que la ventana con cortinas y el espejo que cubría las puertas correderas del armario le enterraran" " ${ }^{4}$ pero aún así Friedrich, "dedicó devota atención a su trabajo". 5

A continuación, en el segundo párrafo, se presenta a Marela que "seguía enferma, le habían dicho, daba pena verla, los pómulos rasgando la piel y las manos amarillas y temblorosas", ${ }^{6}$ pero Friedrich no quiere enfrentarse con su imagen, harto y también culpable de la degradación de Marela, pues en el pasado mantuvieron una relación sentimental. Se cansó, como se está cansando también de su novia Anna. Su trabajo, como para el protagonista de "A subasta" en Juegos míos, es su prioridad, y las mujeres son meros instrumentos: "Marela, Anna, Kristinn, todas similares pese a los distintos cuerpos y las distintas bocas, todas con miedos y tentáculos y familias de domingo." 7

\footnotetext{
${ }^{3}$ Rainer Maria RILKE, Elegias de Duino, Madrid, Cátedra, 2001, 37.

${ }^{4}$ Espido FREIRE, Juegos mios, Madrid, Alfaguara, 2004, 83.

${ }^{5}$ Idem.

${ }^{6}$ Idem.

${ }^{7}$ Ibidem, 84 .
} 
"Voces y espejos" de Espido Freire. Hacia una estética de la perversión en el relato especular

Friedrich suspira, mira de nuevo el relato de Marela, imaginando ya los mismos monstruos de siempre. Decide que hablará con ella, que la decadencia de los últimos meses no puede continuar, y comienza a leer.

Hasta aquí la exposición del relato que se desarrolla de manera lineal. El nudo del relato principal (84-91) comienza precisamente con la exposición del siguiente relato (84-85) inserto a modo de "cajas chinas" o, siguiendo la voz francesa, de mise en abyme esto es, la oeuvre dans l'oeuvre o la duplication intérieur ${ }^{8}$ que veremos más adelante. Así pues, este segundo relato comienza así:

EL MONSTRUO DEL ESPEJO

Para Friedrich Bonn, a quien tanto debo.

Habia un jardín soñoliento tras la ventana, un jardin que yo contemplaba en las tardes de otoño en las que me sentaba tras mi mesa de escribir. La habitación habia quedado vacia, con tan solo un escritorio y el gran espejo que cubría toda la pared derecha [...]. Y luego, lentamente, llena de insomnio y de miedo, volvia los ojos al espejo, comenzaba a trazar letras sobre el folio y gastaba el resto de la noche vigilando cómo mis historias crecían bajo la mirada fija de la gemela alli encerrada. ${ }^{9}$

Aquí el narrador homodiegético, tras el que se esconde Marela, alude al jardín tras la ventana, una constante en Espido Freire que reencontramos en otros relatos o Nos espera la noche. El jardín en Espido Freire es símbolo de un espacio intermedio entre el interior y el exterior, un mundo aún dentro de lo doméstico, pero próximo al misterio, y la ventana como anhelo de lo soñado, de la libertad, frente a la opresión del interior. Encontramos aquí también, como si de un reflejo del espacio real de Friedrich se tratara, el espejo que nos acompañará a lo largo de todo el relato, frente al que ella, en un acto puramente decadente, escribe sus relatos. A su vez, el doble, el eterno alter ego, que se proyecta en su espejo. El propio título del relato "El monstruo del espejo", es una autorreferencia a los relatos que componen "Bestiario" en Juegos míos.

Esta exposición se intercala con la narración principal, aséptica, en tercera persona. Pero la interacción entre ambos niveles de la narración resulta evidente, si bien al inicio resulta sólo una insinuación. Así, Friedrich observa "los espejos del armario, espejos por todas partes, que le contemplaban lejano y ausente, y que amenazaban con tragarse su cuerpo entre las sombras". ${ }^{10}$

El nudo propiamente dicho del relato secundario comienza con la llegada de las voces (85-91): "aparecian tras las puertas de los espejos, invitadas por lo oscuro, por los confusos compases de los valses que yo escuchaba". ${ }^{11}$ Las voces, como las musas, son siete, inspiradoras del escritor, de Marela, "esperando a que las saludara y las invitara a contarme historias y leyendas. A eso venían."12 Llegan además con música de vals, que tiene un papel

\footnotetext{
${ }^{8}$ Lucien DÄLLENBACH, Le recit spéculaire, París, Seuil, 1977, 31.

${ }^{9}$ FREIRE, op. cit., 84-85. Nótense las cursivas de la autora presentes en todo el récit second, como diferenciación respecto al relato principal.

${ }^{10}$ Ibidem, 85.

${ }^{11}$ Idem.

12 Idem.
} 
importante en la construcción del tiempo narrativo y de la atmósfera al marcar un ritmo circular progresivamente envolvente. La iniciación comenzó tiempo atrás, en la niñez, como también encontramos en Diabulus in musica, pero las voces llegan más tarde, por razones diferentes: "Las voces sólo aparecieron cuando descubri que ese reflejo inexplicable y de ojos grandes al otro lado del espejo, la dócil muñeca que habia crecido calcando mis formas tras el cristal me miraba con pena desde su puerta del universo paralelo al verme rompiendo bojas escritas, desesperada por la sequía de mi mente." 13

Es la imagen en el espejo la inductora de perversión. Es ella la que llama a las voces en busca de inspiración. Esta visión del espejo contrasta radicalmente con la de Friedrich: "él, por ejemplo, bromeaba con su imagen y se daba ánimos cada mañana, sin dedicarle mucho tiempo, y para eso servía un espejo, y punto". ${ }^{14}$ Esta es la base de la oposición entre el récit premier y el récit second: El mundo de Friedrich alude a lo práctico, lo realista, lo masculino. El de Marela a lo imaginario, decadente y "femenino". "Además, el tema del doble maldito había sido empleado hasta la saciedad, y por autores con mayor prestigio y habilidad que ella." 15 Como veremos, Borges y Cortázar son dos de los grandes maestros del espejo y la duplicación del yo.

Las voces beben su sangre, metáfora a lo Truman Capote del don del artista que le lleva a la destrucción: "de todos los precios el que yo pagaba era el más alto". ${ }^{16}$ Ella mientras desearía volver a los tiempos en los que sólo miraba tras la ventana el jardín. Friedrich observa sus venas.

Ella observa su espejo, el único lugar donde puede esconderse. Friedrich contempla su propio espejo. "Se sintió inquieto." 17 El relato sigue poco a poco reflejándose peligrosamente en la realidad de Friedrich. Pero las voces siguen. Vienen, a ritmo de vals a por ella: "Es tu turno. Morirás primero en el espejo, tal y como nuestro trato especificaba. Primero será una sombra oscura, luego una buella de plata. Así sabrás cómo regular tu tiempo." 18 Mientras tanto "el vals continuaba flotando" 19 y Friedrich se cansa de contar los siete leitmotive de Marela: la tierra, el espejo, la música, la mujer de negro, el universo paralelo, la sangre, la muerte... ${ }^{20}$ y precisamente esos son los elementos constantes en Espido Freire. Estamos pues ante un relato metaliterario y autorreferencial. A Friedrich se le pasa por la cabeza parar, "pero le venció la disciplina y se decidió a terminar el cuento

\footnotetext{
13 Ibidem, 86.

${ }^{14}$ Idem.

15 Idem.

${ }^{16}$ Ibidem, 87.

${ }^{17} \mathrm{Idem}$.

18 Idem. La misma imagen la encontramos con diferentes variantes en la sección "Espejos" de Cuentos malvados: "Yo me movía, yo quería irme y me movía, pero la imagen del espejo estaba petrificada y grisácea, y comprendí que habia muerto, y que a mí, la imagen viva, se me agotaba el tiempo" (92).

${ }^{19}$ Ibidem, 88.

${ }^{20}$ Véase la sección "Bestiario" en Juegos mios donde se abordan casi todos estos motivos como monstruos invisibles.
} 
"Voces y espejos" de Espido Freire. Hacia una estética de la perversión en el relato especular

antes de iniciar otra tarea". ${ }^{21}$ Friedrich, el gran devoto del trabajo, hará de su disciplina su verdugo.

Como en Virginia Woolf "Las horas llegan, todas las horas llegan",22 dicen las voces. El tiempo huye. Pero ella se resiste. Se rebela: "sentí pena y despecho, y furiosos deseos de hacer mal". ${ }^{23}$ A Friedrich le parece absurdo: "Por favor, algo nuevo, pensó él, algo con más vigor y menos femenino", ${ }^{24}$ lo cual remite de nuevo a los dos planos opuestos entre uno y otro. La perversión como lo femenino. Pero Marela pide un último deseo. No quiere irse sola. Las voces caprichosas discuten. Aceptan el trato. "Estwo mal. Reconozco que fui perversa; pero nunca dije que fuera buena. Me senté con calma, pidiendo un hipócrita perdón mental. El vals continuaba girando, y yo miré las fotografias en mi mano. Al otro lado del espejo, ella me bizo un ademán de asentimiento, y sonreimos las dos, aliviadas de nuevo [...]. Dije un nombre, y las voces desaparecieron. La babitación estaba vacía, sólo quedábamos alli yo y un espejo, una historia a medias y un jardín oscuro tras la ventana." 25

La perversión es en Espido Freire una opción voluntaria. Existe un elemento de opresión pero no se justifican las acciones, que resultan desproporcionadas. ${ }^{26}$ Estamos ante un personaje femenino a caballo entre la mujer perversa que se deleita en el mal, sin ningún tipo de sentido de culpa, y una especie de "víctima-verdugo", que se rebela contra una doble opresión: el que fue su novio, que no vio en ella más que un objeto, y las voces que la atormentan. La hipocresía, los fingimientos y la ambigüedad a la que juegan los personajes femeninos es evidente. El vals, esa danza que se baila en círculos, volviendo siempre al mismo punto, nos envuelve, nos acorrala de modo macabro, del mismo modo que en su novela Irlanda. Es la danza de las musas y de las parcas. La muerte se acerca sin vuelta atrás y el espejo, la imagen de lo tórrido proyectado, acepta y asume la muerte ajena como algo necesario, un principio vital que, como a los vampiros, le permite renacer. Una vida más, "aliviadas de nuevo", pues hubo antes otros, y otros más habrá. Como en un orgasmo salvaje, tras el caos vuelve el orden: ella, su espejo, una historia, un jardín tras la ventana. La catarsis de la muerte les ha regenerado. $\mathrm{El}$ asesinato pone fin a las voces y al reflejo inductores de mal, que siguen un camino conocido por Marela. "La música se frenó. En el silencio, el nombre dicho se había detenido. Friedrich Bonn.” 27

\footnotetext{
${ }^{21}$ FREIRE, op. cit., 88.

${ }^{22}$ Idem. Véase La señora Dalloway de Virginia Woolf, cuyo título provisional fue precisamente Las horas pues son las horas del día las que marcan el devenir incierto de Clarissa, que se debate interiormente en un conflicto entre la vida y la muerte.

${ }^{23}$ FREIRE, op. cit., 89.

${ }^{24}$ Idem.

${ }^{25}$ Ibidem, 90.

${ }^{26}$ Remitimos al lector interesado a este respecto a nuestro artículo de próxima publicación "Perversión y muerte como fundamento narrativo en la obra de Espido Freire", in: Cultura Iberoamericana, Tomus XXVIII, Valladolid, 2014.
}

${ }^{27}$ FREIRE, op. cit., 90. 
La música construye la atmósfera en espacios circulares macabros que remiten a la muerte. Estamos ante una seducción de los sentidos que nos conducen irremisiblemente al golpe letal del clímax. Y precisamente es aquí donde se fusionan para siempre el relato principal y el "secundario". El clímax de ambas historias se une (91-92), y esta vez no frente al espejo de Marela. Así pues, Friedrich sonríe ante la ocurrencia: "no era un cuento que tuviera intención de publicar, sino un acto de venganza menudo y aburrido, una infamia más, un modo de llamar su atención [...]". ${ }^{28}$ Le recuerda la época en la que estuvieron juntos, los guiños literarios, las lecturas cómplices. "Pero no continuó leyendo. No veía las letras. Se frotó los ojos, cansado, y se acercó al espejo. Desde luego, era tarde. Dio la espalda al armario, pero se volvió bruscamente. La imagen no se había movido. Sonrió. Era el cuento. Las voces comenzaban a afectarle. Levantó la mano, pero en el espejo no hubo cambio esta vez. Estupefacto, vio cómo el reflejo movía la cabeza, tristemente, y se hacía a un lado [...]. Las voces fueron apareciendo hasta llenar el pequeño cuarto [...]. Notó que la cordura se le escapaba de la garganta. Poco a poco, sin prisa, se acercaron a él." 29

Como una imagen proyectada de la historia de Marela, es él ahora el que se ve envuelto en un reflejo imposible en el espejo. Muy sutilmente, el cuento en el cuento ha ido penetrando el universo supuestamente real. El orden desaparece en nuestra realidad al tiempo que se restituye en el universo paralelo de Marela. El reflejo no se mueve, y las voces llegan, lentamente, hasta él.

Marela, del otro lado, termina su historia, cómplice con el espejo. El clímax macabro da paso a una progresión descendente, taimada, en la que Marela medita resignada sobre tanto fingimiento "en los últimos meses", como se dice al inicio, "cuando volcaba sangre robada en cada relato".30 Es una psicópata literaria. "Las voces estaban entusiasmadas, para Friedrich comenzaba el tormento que ella había sufrido durante varios años." 31 Es decir, volvemos al punto de partida, vidas que se reencuentran hasta el infinito.

La perspectiva en este relato nos remite a la técnica de las cajas chinas o, según la voz francesa, la mise en abyme, asociada a la figura especular, al eterno espejo que nos devuelve nuestro reflejo, ${ }^{32}$ que tan minuciosamente ha estudiado Lucien Dällenbach. Este autor habla de tres tipos de ajustes (emboîtements) de la mise en abyme: el diégétique (o intradiégétique), el métadiegétique y el méta-récit (o récit sécond) réflexif. ${ }^{33}$ Es el último tipo, el méta-récit réflexif que nos interesa en este relato. Dällenbach lo define así: "Le méta-récit réfléxif tel que nous l'entendons se caractérise par sa quadruple propriété de réfléchir le récit, de le couper,

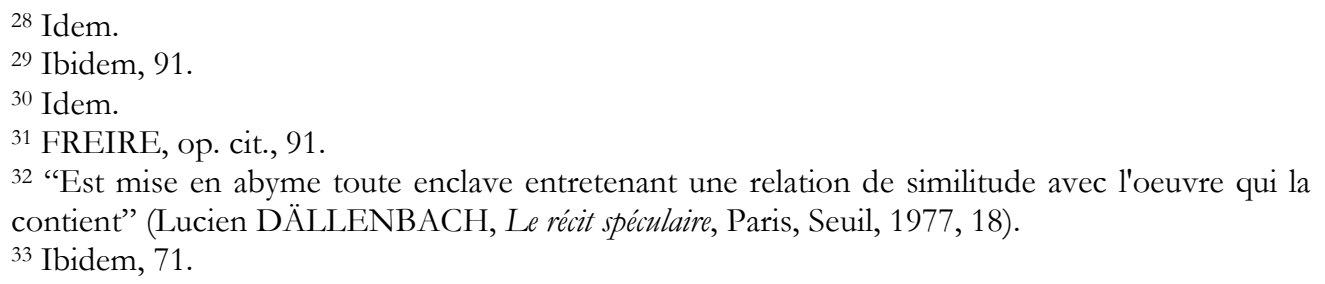


"Voces y espejos" de Espido Freire. Hacia una estética de la perversión en el relato especular

d'interrompre la diégèse et [...] d'introduire dans le discours un facteur de diversification. Censée d'être prise en charge par une instance narrative différente de celle qui gouverne le récit premier, l'insertion, qui peut être orale (a) ou écrite (b), légitime de la sorte les variations stylistiques (c) en même temps qu'elle permet d'injecter un récit personnel dans une fiction écrite à la troisième personne (d) [...]." 34

$\mathrm{Y}$ es precisamente lo que sucede aquí. La diégesis se interrumpe y encontramos una instancia narrativa diferente, un nuevo narrador en primera persona de estilo bien diferente, marcado por lo fantástico, frente al narrador heterodiegético del relato principal, sumido en la realidad inmediata. Anderson Imbert compara ambos relatos con el círculo. La situación inicial se asocia al círculo mayor, el externo, frente al segundo narrador, adscrito a un segundo círculo interno, aunque puede haber infinitos círculos insertos unos en otros, ${ }^{35}$ donde existen diferentes modos de relación entre los dos (o más) planos narrativos. Genette habla de tres que a su vez retoma Anderson Imbert: cuando la acción del segundo es consecuencia del primero es una función "explicativa". Cuando el segundo no se relaciona con la diégesis del primero pero existen semejanzas en la función es temática. Finalmente, existe un tercer tipo, como en Las mil y una Noches, donde se unen historias tras otras en cadena sin mayor vínculo que un narrador que las va contando. ${ }^{36}$ En este relato el vínculo parece a priori inexistente. Es el cuento dentro del cuento de Las mil y una Noches, pero la ficción del segundo círculo poco a poco se apodera del primero, y al final la diégesis del récit second prevalece. La fantasía más perversa ha vencido frente a la realidad. Es lo que Genette denomina métalepse narrative. ${ }^{37}$ Los personajes de la historia secundaria cobran vida y escinden las fronteras entre realidad y ficción. Es ese relato en abyme el que en realidad ha conducido el relato supuestamente principal. Se trata de un golpe final que ha sido objeto de crítica $^{38}$ y que sitúa a este relato entre uno de los pocos en Espido Freire donde lo irreal llega a trascender el plano de la sugerencia. Parte de lo cotidiano y se revela fantástico, lo cual nos remite a otros relatos, como "La continuidad de los parques" en Final del juego de Julio Cortázar. Aquí, el lector sentado cómodamente en su sillón de terciopelo verde lee una novela: "la ilusión novelesca lo ganó casi en seguida. Gozaba del placer casi perverso de irse desgajando línea a línea de lo que lo rodeaba, y sentir a la vez que su cabeza descansaba cómodamente en el terciopelo del alto respaldo [...]." 39 Una mujer y un amante se dan cita. Tras momentos de caricias y pasión ella se marcha y le

\footnotetext{
${ }^{34}$ Idem.

${ }^{35}$ Enrique ANDERSON IMBERT, Teoría y técnica del cuento, París, Ariel, 1992, 60.

${ }^{36}$ GENETTE, op. cit. 241-243 y DÄLLENBACH, op. cit., 159-160.

37 Ibidem, 244.

38 "Si uno repasa los que me parecen mejores cuentos encuentra que son aquéllos en los que no ha pretendido ser demasiado original, y no han provocado ninguna clase de efectos especiales [...]. Se trata por tanto de sorprender con finales inesperados" (José María POZUELO YVANCOS, "Perversas", ABC Blanco y negro cultural, Madrid, 2004, 9.

${ }^{39}$ Julio CORTÁZAR, Final del juego, Buenos Aires, Editorial Sudamericana, 1976, 9.
} 
indica el camino. Ha de matar al marido: "La puerta del salón, y entonces, el puñal en la mano, la luz en los ventanales, el alto respaldo de un sillón de terciopelo verde, la cabeza del hombre en el sillón leyendo una novela." ${ }^{40}$ Son dos páginas nada más, pero el lector, como el personaje del lector del cuento, se deja subyugar por la historia de final sorprendente. A diferencia de Espido Freire, el cuento dentro del cuento aquí no se expone en estilo directo sino indirecto, pero en Cortázar gana en intensidad, brevedad y unidad de efecto, tríada del buen cuento en Poe ${ }^{41}$ y que Espido Freire retoma. ${ }^{42} \mathrm{La}$ "metalepsis" implica por tanto la negación de las leyes físicas, y el miedo a que vivamos un mundo que no es el que creemos, otra constante borgiana.

Pero retomemos el tema de las voces y los espejos. Las voces son, ya lo hemos dicho, especies de musas caprichosas y cruentas. Como las voces que escuchaba Virginia Woolf, son confusas y en Espido Freire siempre inductoras del mal. En la sección "Las voces" en Cuentos malvados encontramos un compendio del imaginario espidiano sobre las voces: "Las voces le contaron cómo día tras día, hora tras hora, el tiempo roería sus huesos, girando en su cabeza, y que un día encontraría sus huesos desnudos y su cabeza vacía jugando con el tiempo, y finalmente le alentaron a liberarse de toda aquella asquerosa carne." 43

Como las voces de Marela, se alimentan de sangre, del sufrimiento humano. Atormentan a sus víctimas hasta lograr su muerte. La diferencia es que en este relato las voces no conducen al suicidio sino al asesinato.

Dentro de este imaginario de perversión el espejo se convierte en un elemento esencial. Aquí el espejo tiene dos valores: es el instrumento físico que duplica el yo frente a su alter ego con vida propia. Esta misma idea está presente en la sección "El espejo" en Cuentos malvados que además se relaciona con el elemento fantástico de las voces: "Me habla cada mañana, y cada noche, y ya no puedo resistirlo. Hoy cruzaré al otro lado con ella, con mi gemela, y me asomaré a sus cristales, a todos los cristales del mundo, e iniciaré la larga ronda llamándoles, ven, ven, ven..." 44

"Una flor amarilla" en Final del juego de Cortázar aborda también el encuentro entre el personaje consigo mismo pero mucho más joven, en una superposición de planos imposibles. En "Todos los fuegos el fuego" en el libro homónimo, Cortázar va más allá y se plantea un concepto absolutamente borgiano: todos los hombres en un mismo hombre, es decir, la vida como repetición infinita en el tiempo. Es lo que se trasluce en

\footnotetext{
40 Ibidem, 10.

${ }^{41}$ Edgar Allan POE, Ensayos y críticas. Ed. y trad. de Julio Cortázar, Madrid, Alianza, 1973, 125 y 135-136.

42 Espido Freire afirma que "lo que caracteriza principalmente el cuento es su intensidad, es su brevedad y es la capacidad de sorpresa" (FREIRE, op. cit., "El cuento").

${ }^{43}$ Espido FREIRE, Cuentos malvados, Madrid, Suma de Letras, 2003, 57.

${ }^{44}$ Ibidem, 90. Cursivas indicadas en el texto original. Nótese que Espido Freire, como en el récit second de "Voces y espejos", recurre a esta tipología de letra para marcar la diferencia entre las voces imaginarias y el universo real.
} 
"Voces y espejos" de Espido Freire. Hacia una estética de la perversión en el relato especular

"Los teólogos" (El Aleph) o "El jardín de senderos que se bifurcan" (Ficciones) de Borges, donde afirma que "creía en infinitas series de tiempos, en una red creciente y vertiginosa de tiempos divergentes, convergentes y paralelos". ${ }^{45} \mathrm{El}$ uso del espejo en Borges, como en Espido Freire, obedece a la expresión de la pluralidad del yo ${ }^{46}$ que remite a la concepción de la vida, el universo, entendido como un laberinto inescrutable ${ }^{47}$ y un tiempo eterno. En Espido Freire encontramos también un matiz de miedo al yo perverso reflejado en el espejo, que recuerda la fobia de Virginia Woolf a los espejos y que, sin embargo, tan presentes están en sus relatos. ${ }^{48}$

Espido Freire, como Marela, hace del espejo una constante. La transtextualidad y las autorreferencias son evidentes en este relato. El espejo es además la esencia de la mise en abyme, son de hecho equivalentes. ${ }^{49} \mathrm{El}$ espejo nos devuelve una imagen, la nuestra, en una ilusión de realidad que se revela ficticia. Pero en ocasiones resulta tan real... Si empleamos varios espejos obtendremos una visión caleidoscópica, múltiple. Es lo que el profesor García Galiano ha denominado como "polifonía textual” 50 y que sobrepasa la metáfora en el relato "Sinfonía" en Juegos míos.

Aquí no hay únicamente dos círculos, las historias se multiplican con el espejo: Marela y su espejo, Friedrich y su espejo, y a su vez el espejo de Marela como puente hacia el espejo de Friedrich. La historia continúa. El espejo y las voces traerán más muertes. Estamos ante un tiempo en eterno retorno. Como en la alegoría, "el final de la historia sólo es referible en metáforas, ya que pasa en el reino de los cielos, donde no hay tiempo". 51

El carácter metaliterario también está multiplicado por la mise en abyme: el editor que lee a la escritora y la escritora que escribe sobre la escritura. El desdoblamiento sensorial tal y como ocurre entre narrador-autor, narrataire-lector ${ }^{52}$ y que Jauss retoma como elementos fundamentales de la tríada autor-texto-lector. ${ }^{53}$ Aquí se desarrolla un

\footnotetext{
45 Jorge Luis BORGES, Ficciones, Madrid, Espasa, 1999, 86.

46 Véase "Los espejos velados" y "Los espejos" en El hacedor.

47 Sirvan como ejemplos "La casa de Asterión", "Abenjacán el Bojarí, muerto en su laberinto" o "Los dos reyes y los dos laberintos" en El Aleph, 1949 o "La biblioteca de Babel" en Ficciones, 1944, entre otros muchos relatos. Véase también la sección "Dentro del laberinto" en Cuentos malvados donde Espido Freire reinterprea el mito del minotauro dentro de un tiempo y espacio infinitos.

48 "La gente no debería dejar espejos colgados en las habitaciones, como tampoco debería dejar abiertos talonarios de cheques o cartas en las que confiesa algún horrible delito" dice Virginia Woolf en su relato "La mujer del espejo" (Virginia WOOLF, Relatos completos, Madrid, Alianza, 1994, 87). Esta idea entronca con el pudor represivo victoriano que ella misma reconoce y el miedo a ver una verdad profunda, desnuda, impúdica, frente al espejo, como sucede en Espido Freire.

${ }^{49}$ DÄLLENBACH, op. cit., 215.

50 Ángel GARCÍA GALIANO, "La nueva narrativa bilbaína ante el tercer milenio: Espido Freire", in: Bilbao. El espacio lingüístico. Simposio 700 Aniversario, Bilbao, 2002, 460.

${ }^{51}$ Jorge Luis BORGES, "Los teólogos", in: El Aleph, Madrid, 1971, 48.

${ }^{52}$ GENETTE, op. cit., 264-274.

${ }^{53}$ Hans Robert JAUSS, Pour une esthétique de la réception, París, Gallimard, 1990, 53.
}

60 | Acta Hispanica 19: 51-61, 2014, ISSN: 1416-7263 
juego de encuentros y desencuentros con uno mismo a través del espejo físico y metafórico que apunta hacia una categoría superior: la Literatura como espejo de una supuesta realidad, la alegoría vital.

"Voces y espejos" es, pues, un relato que recoge las obsesiones que pueblan el imaginario literario de Espido Freire, esto es, las voces y los espejos como inductores del mal. La mise en abyme o el relato especular en tanto que desdoblamiento narrativo permite a la autora el desarrollo de un alter ego, tan querido por Borges o Cortázar, y que aquí apunta a una voz oculta en nosotros, sutil, apenas perceptible, pero siempre perversa, y que el espejo se encarga de reflejar peligrosamente. Este relato presenta además la particularidad de emplear una mise en abyme doble por su carácter metaliterario, que remite a la propia concepción y recepción del relato dentro de un triángulo macabro entre autor, texto y lector.

"Voces y espejos", nos transporta, pues, a un laberinto imposible de perversión, que no puede concluir más que en tragedia. 